\title{
Infrastructure Asset Management: Referees 2018
}

The following is a list of referees who have reviewed papers for Infrastructure Asset Management between 1 December 2017 and 30 November 2018. The Institution of Civil Engineers (ICE) is very grateful for their assistance.

We are continually looking for suitable reviewers for papers submitted to Infrastructure Asset Management. Papers published in the ICE journals must be submitted to at least two independent referees to judge accuracy, style, impact, importance and interest.

Bryan Adey

Elshan Ahani

Bortiorkor Alabi

Shafiq Alam

Saeed Alqadhi

Zaid Alyami

Md. Shohel Amin

Robin Andrew

Bernard Aritua

Sana Balouch

Jonathan Bateman

Frederick Bloetscher

Carron Blom

Andrew Brown

Marcel Burkhalter

Neil Carhart

Chen-Yu Chang

Panos Chountalas

Qingbin Cui
Mike Dixon

Craig Ellis

Mehran Eskandari Torbaghan

Jonathan Foster-Clark

Borja García de Soto

Koorosh Gharehbaghi

Jose Gobbo

Michael Goodfellow-Smith

Cameron Gordon

Nico Grove

Peter Hallsworth

Timo Hartmann

Oliver Heidrich

lan Jenkinson

Heather Jones

Golam Kabir

Mike Kagioglou

Maria Kakouratou

Pushpitha Kalutara

If you are interested in reviewing articles on any topic related to infrastructure asset management, please submit your name, qualifications or CV, and areas of expertise. We are in need of individuals who will agree to review papers in a timely fashion (within 3 to 4 weeks of receipt) and provide confidential feedback to the Editorial Advisory Panel concerning the quality of the paper and any suggested revisions that would be appropriate.

If you are such a person, please contact Kirsten Buchanan (tel.: +44 (0)207 665 2204; e-mail: kirsten.buchanan@icepublishing.com) for more information on the referee process.

Murat Karacasu

Hirushie Karunathilake

John Khoury

Clemens Kielhauser

Andy Kirwan

Praveen Kumar

Samuel Labi

Norberto Levin

Mohammad Mahoud

Lewis Makana

Steven Male

Rajib Mallick

Rahul Marate

Rui Marques

Jamie Maslen

Tariq Masood

Frank Meissner

Krisen Moodley

Alfredo Nunez
Aleli Osorio-Lird

Aristeidis Pantelias

Natalia Papathanasiou

Jennie Phillips

Andy Pike

Ali Saeed

Tariq Usman Saeed

Xiomara Sanchez-Castillo

Manuel Schafer

Graham Thrower

Eric Too

Cristina Torres

Kieran Tully

John Woodhouse

George Yannis

Xian-Xun Yuan

Yajian Zhang

Zhanmin Zhang 